\title{
EVOLUÇÃO DO CRESCIMENTO ECONÔMICO DOS MUNICÍPIOS DO RIO GRANDE DO SUL ${ }^{1}$
}

Valter José Stülp

Resumo - Este estudo analisa a convergência, ou não, dos municípios do Rio Grande do Sul para um mesmo nível de renda per capita, bem como fatores que possam explicar o seu crescimento econômico, como a localização regional, a participação dos setores na atividade econômica e a estrutura agrária. As perspectivas de crescimento econômico regional no Estado são otimistas. A participação dos municípios localizados acima da renda per capita média do Estado aumentaria, no futuro, de $28 \%$ para $52 \%$. Com exceção da região noroeste do Estado, nas demais, o efeito direto dos setores indústria e de serviços sobre a renda foi maior do que o da agropecuária. Porém, esta merece destaque porque, além de sua contribuição direta, a sua atuação ocorre também via setor industrial e de serviços, por meio de atividades como borracha, fumo, couro, calçados, alimentos, bebidas e comércio varejista. A renda cresceu a taxas maiores nas regiões onde predominavam os estabelecimentos rurais menores.

Palavras-chave: crescimento econômico, municípios, convergência regional.

\section{Introdução}

O simples crescimento da renda per capita não pode ser considerado desenvolvimento econômico, porque, conforme Souza (1995, p.17), "desenvolvimento econômico se define, portanto, pela existência de crescimento econômico $(\mathrm{g})$ em ritmo superior ao crescimento demográfico $\left(\mathrm{g}^{*}\right)$, envolvendo mudanças de estruturas e melhoria de indicadores econômicos e sociais per capita". Apesar de, isoladamente, não definir

Recebido em 31/10/2005. Aceito em 06/12/2005.

2 Professor do Departamento de Ciências Econômicas - FACE - PUCRS. Esta pesquisa contou com auxilio do CNPq e uma bolsa de iniciação científica da FAPERGS. 
o desenvolvimento econômico, "tradicionalmente, a renda per capita tem sido usada como o principal indicador de desenvolvimento" (Souza, 1995, p.18).

Accurso (2002) observou que, no Rio Grande do Sul, o produto interno bruto (PIB) cresceu a uma taxa média anual de 3,2\% no período de 1990-97, superior, portanto, à brasileira, que foi de 3,0\%. O PIB per capita do Estado cresceu a uma taxa média anual de 2,1\% e o do Brasil, à taxa de $1,5 \%$ no mesmo período.

Embora o desempenho do Estado, em termos de crescimento do PIB e PIB per capita, tenha sido superior ao do país, o mesmo não foi uniformemente distribuído entre as regiões. Bastos (2002) observou que as taxas de crescimento médio anual do valor adicionado bruto real (VAB) das 22 regiões do Estado, designadas de Conselhos Regionais de Desenvolvimento (Coredes), variaram de 7,05\% a.a. (Corede de Paranhana) a 0,37\% a.a. (Corede Litoral), de 1990 a 1998.

Houve também grandes diferenças entre as regiões do Estado, quanto às taxas anuais do crescimento populacional. Jardim (2000) calculou essas taxas por microrregiões do Estado, no período de 1991-96, as quais variaram de 3,14\% a.a. (Microrregião Gramado-Canela) a -1,07\% a.a. (Microrregião Três Passos).

Considerando as grandes diferenças regionais nas taxas de crescimento do produto e da população ocorridas na década de noventa, questiona-se se haveria convergência futura das regiões do Estado para um mesmo e maior nível de renda per capita.

Stülp e Fochezatto (2003) analisaram a convergência regional da renda per capita no Rio Grande do Sul com base em valores observados nos anos de 1985 e 1999, em nível dos Coredes. A conclusão do estudo foi que, no futuro, as regiões convergiriam para níveis de renda per capita próximos da média estadual. 
A convergência das regiões do Estado, especialmente daquelas com níveis de renda per capita mais baixos, para patamares mais elevados é importante, visto que pode reduzir o ritmo da migração populacional para os grandes centros urbanos do Estado, que apresentam dificuldades para prover condições adequadas de infra-estrutura de saneamento, emprego, atendimento escolar e saúde para os habitantes atuais, e menos ainda para expressivo número de imigrantes.

A questão da convergência entre os níveis de crescimento de países ou regiões, em termos da renda per capita, produtividade da mão-de-obra, etc., é colocada, com freqüência, em estudos sobre crescimento econômico (Baumol, 1986; Barro e Sala-i-Martin, 1991, 1992).

Neste estudo, analisa-se a evolução dos municípios do Estado, quanto ao seu crescimento, fazendo projeções para inferir se os mais atrasados convergirão para níveis mais elevados de renda per capita. Avaliam-se, também, os fatores associados às diferentes taxas de crescimento dos municípios, procurando explicar como se dão a participação dos setores da atividade econômica na estrutura produtiva, a localização regional e a estrutura agrária do município.

O estudo ainda considera o efeito espacial sobre a convergência nos níveis de renda per capita dos municípios, com base na idéia de que uma região pobre, cercada de regiões ricas, poderia evoluir mais rapidamente do que uma região pobre localizada entre pobres.

\section{Metodologia}

No estudo de Stulp e Fochezatto (2003), a análise da convergência regional de renda foi realizada com base nos 22 Coredes do Estado. Como neste estudo se analisam tanto a convergência regional quanto o efeito espacial e outros fatores que possam influir nesta convergência, o número de observações precisa ser maior do que 22. Optou-se, assim, por utilizar os municípios do Estado como unidades de observação. 
A metodologia de análise é baseada em uma matriz de Markov, que permite analisar a convergência regional, a velocidade desta e a existência de possíveis efeitos espaciais.

A renda per capita, neste estudo, é expressa pelo Valor Adicionado Bruto (VAB) municipal, estimado pela Fundação de Economia e Estatística (FEE) do Rio Grande do Sul, dividido pela população.

O período-base de análise compreende 1990 a 2000. Os valores do VAB per capita municipal, de 1990 e de 2000, são expressos pelo valor médio do Estado no respectivo ano, considerado igual a 1,00 (unidade). Essas duas distribuições de VAB per capita, de 1990 e de 2000, são divididas em um mesmo número de classes idênticas de uma distribuição para a outra.

Cada município considerado em 1990 e 2000 deve referir-se à mesma área geográfica, para possibilitar a comparação. Quando isto não ocorrer, porque houve emancipações municipais, considera-se um conjunto de municípios em 2000, que represente a mesma área geográfica.

A matriz de probabilidades de transição de Markov $(M)$ é determinada com base na transição dos municípios de uma classe de VAB per capita para outra, de 1990 a 2000. Indica a probabilidade de cada município da classe de VAB per capita $i$, no tempo $t$, estar na classe $j$, no tempo $t+1$. Sendo $F_{t}$ a distribuição regional do VAB per capita no tempo $t$ e $F_{t+1}$ a distribuição no tempo $t+1$, é possível elaborar o sistema de equações de diferenças que expressa a evolução da distribuição ao longo do tempo, representado por

$$
F_{t+1}=M F_{t}
$$

A solução deste sistema informa sobre o processo de convergência dos municípios quanto ao VAB per capita, bem como sua velocidade (Simon e Blume, 1994, cap.23). 
Para determinar a dimensão $h$ do intervalo das classes de VAB per capita, em cada uma das duas distribuições, utiliza-se a expressão recomendada por Devroye e Györfi (1985, apud Magrini 1999, p.264):

$$
h=2,72 s n^{-1 / 3},
$$

em que s é o desvio-padrão da distribuição e $n$, número de observações.

Segundo esses autores, a expressão (2) seria especialmente indicada, se a distribuição fosse normal, mas seria adequada mesmo nos casos de uma distribuição não-normal.

O efeito espacial sobre a convergência entre regiões tem sido analisado por vários autores (Le Gallo, 2001; Rey, 2001). Para incluí-lo no estudo, consideraram-se as 35 microrregiões homogêneas do Estado, que são classificadas em dois grupos, o das microrregiões com VAB/capita abaixo da média do Estado e o grupo com VAB/capita acima da média.

Cada município é classificado por duas ordens, em relação a 1990 e 2000. Uma ordem determina a sua posição em relação à média do conjunto de municípios e a outra estabelece se ele está inserido em uma Microrregião com valor baixo ou alto de VAB per capita.

Estima-se, também, como o crescimento do VAB per capita dos municípios, de 1990 a 2000, pode ser explicado pelo crescimento dos setores agropecuário, indústria e serviços (fonte FEE). Analisa-se, pela regressão estatística, como as taxas de crescimento do VAB destes setores são, por sua vez, explicadas pela participação das atividades componentes de cada setor, pela localização regional da atividade e pela estrutura agrária do município. 


\section{Resultados}

De 1990 a 2000, 265 regiões permaneceram geograficamente homogêneas. Analisa-se, inicialmente, a convergência ou não destas regiões, em termos de VAB per capita e após a importância relativa das atividades econômicas, localização regional e estrutura agrária para a evolução do $\mathrm{VAB} /$ capita.

\subsection{Convergência regional}

Os valores adicionados brutos a preços básicos (VAB) per capita das 265 regiões, relacionados ao valor médio do Estado, encontram-se no Quadro 1, do anexo.

Aplicou-se o teste de normalidade de Kolmogorov-Smirnov a cada uma das duas distribuições de VAB per capita (Siegel, 1956). O valor absoluto da diferença máxima entre a distribuição de freqüência acumulada observada e a acumulada teórica esperada, na hipótese de normalidade, foi igual a $\mathrm{D}=0,202$, para distribuição de 1990 , e $\mathrm{D}=0,187$, para a de 2000. O valor crítico do teste, para uma amostra de 265 observações e a $1 \%$ de significância estatística, foi de 0,100 (vide tabela E, em Siegel, 1956, p.251). Como cada D observado foi maior que 0,100, rejeitou-se a hipótese de normalidade, a 1\% de significância, em relação a cada uma das duas distribuições.

Mesmo assim, utilizou-se a fórmula (2) no cálculo do intervalo de classe, com base na afirmação de Devroye e Györfi (1985, apud Magrini 1999, p.264), de que a expressão seria adequada também no caso de uma distribuição não-normal.

Para a distribuição de 1990, obteve-se $h=0,41$, e para a de 2000, $h=$ 0,47 . Considerou-se o valor médio de $h=0,44$ para estabelecer intervalos idênticos de cada distribuição. As regiões foram classificadas em quatro 
classes, com intervalos de $\mathrm{VAB} /$ capita, relativos ao valor do Estado: a) 0,00 a 0,55 ; b) 0,56 a 0,99 ; c) 1,00 a 1,44 ; e d) superior a 1,44 .

As regiões também foram classificadas em duas classes adicionais, de acordo com o VAB/capita da Microrregião em que estavam inseridas. Com base na sua migração entre classes, de 1990 a 2000, o sistema de equações de diferenças, conforme a expressão (1), é:

\begin{tabular}{|c|c|c|c|c|c|c|c|c|c|}
\hline $\mathrm{F} 11_{\mathrm{t}+1}$ & 0,282 & 0,222 & 0,028 & 0,037 & 0,000 & 0,000 & 0,000 & 0,000 & $F 11_{t}$ \\
\hline $\mathrm{F} 12_{\mathrm{t}+1}$ & 0,000 & 0,222 & 0,000 & 0,074 & 0,000 & 0,000 & 0,000 & 0,000 & $F 12_{t}$ \\
\hline$F 21_{t+1}$ & 0,692 & 0,167 & 0,770 & 0,185 & 0,278 & 0,074 & 0,250 & 0,000 & $F 21_{t}$ \\
\hline$F 22_{t+1}$ & 0,026 & 0,333 & 0,055 & 0,334 & 0,000 & 0,259 & 0,000 & 0,000 & $F 22_{t}$ \\
\hline$F 31_{t+1}$ & 0,000 & 0,000 & 0,092 & 0,037 & 0,444 & 0,111 & 0,250 & 0,000 & $1_{t}$ \\
\hline$F 32_{t+1}$ & 0,000 & 0,056 & 0,037 & 0,185 & 0,111 & 0,519 & 0,000 & 0,174 & $t_{t}$ \\
\hline$F 41_{t+1}$ & 0,000 & 0,000 & 0,018 & 0,000 & 0,056 & 0,000 & 0,000 & 0,000 & $L_{t}$ \\
\hline$F 42_{t+1}$ & 0,000 & 0,000 & 0,000 & 0,148 & 0,111 & 0,037 & 0,500 & 0,826 & $F 4$ \\
\hline
\end{tabular}

No termos Fij, os $\mathrm{i}=1,2,3,4$ referem-se às classes definidas de acordo com o VAB/capita das regiões relativo ao valor do Estado e os $\mathrm{j}=1,2$, ao $\mathrm{VAB} /$ capita da microrregião em que a região se situa. $\mathrm{O}$ valor $\mathrm{j}=1$ significa que o $\mathrm{VAB} /$ capita da microrregião será inferior e $\mathrm{j}=2$, que $\mathrm{o}$ $\mathrm{VAB} /$ capita da microrregião será superior ao valor do Estado.

Dada a distribuição, existente em 1990, das 265 regiões entre as oito classes, constante na primeira coluna ( $\mathrm{P} 0)$ da Tabela 1 , pode-se determinar a solução definida do sistema de equações de diferenças acima (ver Simon e Blume, 1994, cap.23). Com base nesta solução, elabora-se a Tabela 1, que mostra a evolução das participações relativas das regiões nas diferentes classes de VAB/capita e nas classes de VAB/ capita das microrregiões.

A solução de equilíbrio de longo prazo, constante na última coluna (P26) da Tabela 1, informa que, no futuro, haveria concentração de $45 \%$ das regiões, no segundo nível de $\mathrm{VAB} /$ capita relativo ao valor estadual $(0,56$ a 0,99 ). Apenas $3 \%$ das regiões permaneceriam no nível mais baixo 
(inferior a 0,55$)$ de $\mathrm{VAB} /$ capita. No terceiro (de 1 a 1,44$)$ e quarto (superior a 1,44) níveis de VAB/capita, situariam-se, no longo prazo, $28 \%$ e $24 \%$ do total das regiões.

A Tabela 1 mostra que as regiões com VAB/capita mais baixo (até $0,55)$ evoluem para classes mais altas praticamente com a mesma velocidade, estejam inseridas em microrregiões com VAB/capita inferior (tipo 1) ou superior à média estadual (tipo 2). Assim, o fato de uma região de baixo $\mathrm{VAB} /$ capita estar cercada de regiões com baixos ou altos $\mathrm{VAB} /$ capita não influenciaria a sua possibilidade de evoluir para classes superiores.

As regiões com $\mathrm{VAB} /$ capita acima da média so Estado (de 1 a 1,44 e supeiror) apresentam mior aumento na sua participação no total, quando situadas em microrregiões tipo 2. Assim, uma região com alto VAB/ capita apresentaria maior possibilidade de evoluir para um valor mais alto ou manter-se neste nível, quando cercada de regiões com alto VAB/ capita. 
Valter José Stülp ${ }^{2}$

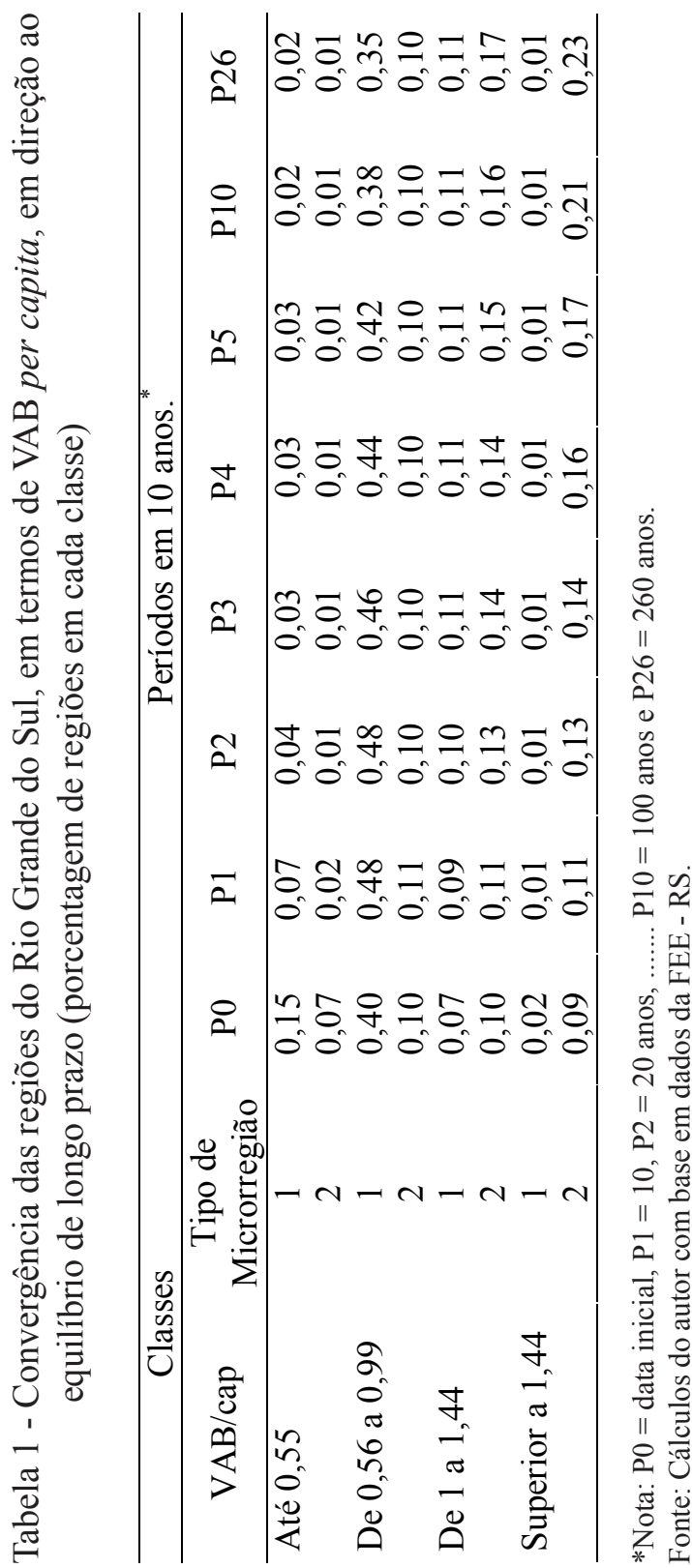


3.2. Os setores da economia e a evolução do VAB/capita

A análise da influência das taxas de crescimento dos VAB dos setores agropecuário, indústria e serviços e do crescimento populacional na evolução do VAB per capita é realizada pelas correlações parciais (Tabela 2).

As correlações parciais foram estimadas para o conjunto de municípios do RS e em relação a três regiões do Estado, aqui designadas por Região Sul, que compreende a Mesorregião Centro Ocidental, Sudeste e Sudoeste Rio-Grandense; Região Nordeste, que compreende a Mesorregião Metropolitana, a Nordeste e a Centro Oriental Rio-Grandense; e a Região Noroeste, formada pela Mesorregião de mesmo nome. As Mesorregiões são definidas pelo Instituto Brasileiro de Geografia e Estatística (IBGE).

Dentre os setores, a taxa de crescimento do VAB do setor de serviços apresentou o maior coeficiente de correlação parcial com a taxa de crescimento do VAB/capita, no período de 1990 a 2000, no Estado e nas regiões Sul e Nordeste. Esse setor é seguido, em ordem de importância, pelo setor industrial e, por último, pelo agropecuário. Porém, o setor agropecuário é o mais importante na região Noroeste, grande produtora de trigo e soja, além de suínos, aves, leite, etc.

O crescimento populacional, evidentemente, influenciou a taxa de crescimento do $\mathrm{VAB} /$ capita, porque constitui o denominador desta variável. 
Tabela 2 - Coeficientes de correlação parcial entre taxa de crescimento do VAB/capita e taxa de crescimento do VAB industrial, do VAB agropecuário, do VAB serviços e da população, no Rio Grande do Sul, entre 1990 e 2000

\begin{tabular}{lcccc}
\hline \multirow{2}{*}{ Região } & \multicolumn{4}{c}{$\begin{array}{c}\text { Coeficientes de correlação parciais entre taxa de } \\
\text { crescimento do VAB/capita e taxas de crescimento }\end{array}$} \\
\cline { 2 - 5 } & $\begin{array}{c}\text { VAB } \\
\text { industrial }\end{array}$ & $\begin{array}{c}\text { VAB } \\
\text { serviços }\end{array}$ & $\begin{array}{c}\text { VAB } \\
\text { agropecuário }\end{array}$ & População \\
\hline Estado & 0,50 & 0,54 & 0,36 & $-0,61$ \\
Sul & 0,69 & 0,75 & 0,40 & $-0,72$ \\
Nordeste & 0,64 & 0,69 & 0,39 & $-0,72$ \\
Noroeste & 0,29 & 0,18 & 0,49 & $-0,42$ \\
\hline
\end{tabular}

Nota: todos os coeficientes são estatisticamente significantes a $1 \%$.

Fonte: cálculos do autor.

Na seqüência, procura-se explicar as taxas de crescimento do VAB da indústria e de serviços por meio das participações dos setores industriais e de serviços nas regiões, medidas por suas concentrações no emprego, expressas pelos quocientes locacionais.

A fonte de dados sobre o emprego é a Relação Anual de Informações Sociais (RAIS) do Ministério do Trabalho e Emprego, referente ao ano 2000.

Em relação à indústria, o quociente locacional do setor industrial i, no municípioj, é dado por

$\mathrm{QL}_{\mathrm{ij}}=\frac{\left(E_{i j} / E_{i}\right)}{\left(E_{j} / E\right)}$,

em que $E_{i j}$ é emprego no setor industrial i da região j; $E_{i}$, emprego no setor industrial i do Rio Grande do Sul; $E_{j}$, emprego em todos os setores industriais da região j; $E$, emprego em todos os setores industriais do Rio Grande do Sul. 
Assim também são calculados os quocientes locacionais dos setores de serviços.

Valores de quociente locacional superiores a 1 indicam que, em relação ao Estado, o município apresentou concentração maior de emprego neste setor, considerado como básico. Caso o valor fosse menor que 1 , o setor não seria básico.

Como variáveis explicativas da taxa de crescimento do VAB agropecuário consideraram-se as variações absolutas regionais nas quantidades produzidas, entre 1990 e 2000, de arroz, feijão, fumo, milho, soja, trigo, uva, maçã, leite e as variações absolutas (em número de cabeças) dos efetivos dos rebanhos bovino, ovino, suíno e aves (galos, galinhas, frangos e pintos).

Consideraram-se também os efeitos diferenciados das regiões Sul e Noroeste, em relação à Nordeste, e a estrutura agrária, expressa pelo percentual dos estabelecimentos rurais da região com área entre $20 \mathrm{e}$ 200 hectares e pelo percentual de estabelecimentos rurais com área superior a 200 hectares, como possíveis variáveis explicativas das taxas de crescimento do VAB industrial, de serviços e agropecuário.

Na Tabela 3 observa-se que, a 10\% de significância estatística, os setores industriais que influenciaram a taxa de crescimento do VAB industrial, entre 1990 e 2000, foram os de mecânica; borracha, fumo e couro; químico; calçados; e alimentos e bebidas.

As regiões do Estado que apresentaram alto percentual de grandes estabelecimentos rurais tiveram menor crescimento industrial em comparação às de minifúndios.

Estes resultados, porém, estão baseadas em uma regressão com $\mathrm{R}^{2}$ ajustado de apenas 0,134. Isto significa que outras variáveis, não consideradas aqui, explicam $87 \%$ da taxa de crescimento industrial no Rio Grande do Sul. 
Tabela 3 - Resultados da regressão da taxa de crescimento do VAB industrial no Rio Grande do Sul, de 1990 a 2000, sobre os quocientes locacionais dos setores industriais quanto a emprego, localização regional da indústria e estrutura agrária

\begin{tabular}{lcc}
\hline Constante e Variáveis & Coeficientes & $\begin{array}{c}\text { Significância } \\
\text { estatística }\end{array}$ \\
\hline 1. Constante & $-8,6882$ & 0,126 \\
2. Quociente locacional da indústria nos & & \\
setores: & 0,1286 & 0,479 \\
2.1. minerais não-metálicos & 0,6145 & 0,356 \\
2.2. indústria metalúrgica & 1,8717 & 0,000 \\
2.3. indústria mecânica & $-0,1812$ & 0,664 \\
2.4. material elétrico e comunicações & 0,5752 & 0,171 \\
2.5. material de transporte & 0,7633 & 0,111 \\
2.6. madeira e mobiliário & $-0,3522$ & 0,496 \\
2.7. papel, editorial e gráfica & 1,6698 & 0,003 \\
2.8. borracha, fumo e couro & 1,3459 & 0,030 \\
2.9. indústria química & $-0,0008$ & 0,998 \\
2.10. indústria têxtil & 3,2254 & 0,018 \\
2.11. indústria de calçados & 1,9373 & 0,049 \\
2.12. alimentos e bebidas & & \\
Efeito diferenciado das regiões: & $-2,5419$ & 0,207 \\
3.1. Sul & $-1,4833$ & 0,274 \\
3.2. Noroeste & 3,5064 & 0,511 \\
4. Percentual de estabelecimentos entre 20 e & $-18,1907$ & 0,016 \\
200 ha & & \\
5. Percentual de estabelecimentos acima de & & \\
200 ha & & \\
\hline
\end{tabular}

Nota: o $\mathrm{R}^{2}$ ajustado da regressão é igual a 0,134 .

Fonte: cálculos do autor. 
A Tabela 4 mostra que os setores que influenciaram, positivamente, a taxa de crescimento do VAB serviços foram os de serviços de utilidade pública; construção civil; comércio varejista; administração técnica e profissional; e administração pública. O setor instituições financeiras teve impacto negativo na taxa de crescimento do VAB serviços.

$\mathrm{O}$ setor serviços apresentou menor crescimento nas regiões Sul e Noroeste, em comparação com a Nordeste. Nas regiões com estabelecimentos rurais menores, a taxa de crescimento do VAB de serviços foi maior.

Tabela 4 - Resultados da regressão da taxa de crescimento do VAB serviços no Rio Grande do Sul, entre 1990 e 2000, sobre os quocientes locacionais dos setores de serviços quanto a emprego, localização regional dos serviços e estrutura agrária

\begin{tabular}{lcc}
\hline \multicolumn{1}{c}{ Constante e Variáveis } & Coeficientes & $\begin{array}{c}\text { Significância } \\
\text { estatística }\end{array}$ \\
\hline 1. Constante & $-2,9739$ & 0,380 \\
2. Quociente locacional dos setores de serviços: & & \\
2.1. serviços de utilidade pública & 0,1753 & 0,006 \\
2.2. construção civil & 0,4769 & 0,020 \\
2.3. comércio varejista & 2,0854 & 0,005 \\
2.4. comércio atacadista & 0,2288 & 0,130 \\
2.5. instituições financeiras & $-0,7832$ & 0,000 \\
2.6. administração técnica e profissional & 1,0692 & 0,001 \\
2.7. transportes e comunicações & 0,3950 & 0,224 \\
2.8. alojamento e comunicação & 0,6289 & 0,157 \\
2.9. medicina, odontologia e veterinária & 0,3808 & 0,227 \\
2.10. administração pública & 2,1025 & 0,022 \\
3. Efeito diferenciado das regiões: & & \\
3.1. Sul & $-1,0926$ & 0,010 \\
3.2. Noroeste & $-1,7088$ & 0,000 \\
4. Percentual estabelecimentos entre 20 e 200 ha. & 1,9086 & 0,082 \\
5. Percentual estabelecimentos acima de 200 ha. & $-3,8229$ & 0,024 \\
\hline
\end{tabular}

Nota: o $\mathrm{R}^{2}$ ajustado da regressão é igual a 0,310 .

Fonte: cálculos do autor. 
A Tabela 5 mostra que as culturas que apresentaram impactos positivos na taxa de crescimento do VAB agrícola foram fumo, soja, trigo e uva. A produção de fumo, no Rio Grande do Sul, aumentou 44\%, de 1990 a 2000.

De 1990 a 2000, a soja e o trigo tiveram queda de produção no Estado, cada qual de $24 \%$ neste período, e também redução nos preços, em termos reais. A área cultivada do trigo apresentou redução de $44 \%$, porém aumento de produtividade de $35 \%$. Assim, o impacto positivo do trigo no VAB agrícola talvez possa ser explicado pela migração da cultura para regiões mais adequadas e com maior produtividade e onde o acréscimo de produção teve impacto positivo no VAB agropecuário.

A área da soja teve redução de $15 \%$ e a de produtividade, de $11 \%$. O coeficiente de correlação entre as variações da área do trigo e da soja, calculado com base nas 265 regiões do Estado, foi de 0,66. Isto permite concluir que a realocação dessas duas culturas entre as regiões do Estado, de 1990 a 2000, se deu na mesma direção, ou seja, para regiões onde o seu incremento de produção teve efeito positivo sobre a variação do VAB agropecuário.

A produção da uva ficou praticamente no mesmo nível, de 1990 a 2000. O efeito da uva sobre o VAB agrícola pode ser devido à substituição das variedades comuns, cujo produto teve preço mais baixo, e das variedades viníferas, cujo produto apresentou cotação mais elevada. 
Tabela 5 - Resultados da regressão da taxa de crescimento do VAB da agropecuária no Rio Grande do Sul, entre 1990 e 2000, sobre as variações regionais nas quantidades de produtos agropecuários e nos efetivos dos rebanhos, localização regional da produção e estrutura agrária

Fonte: cálculos do autor.

Os rebanhos bovino, suíno e de aves influenciaram, positivamente, o crescimento do setor agrícola, enquanto o de ovinos teve influência negativa. Os efetivos de suínos e aves apresentaram, de 1990 a 2000, aumentos de, respectivamente, $10 \%$ e $44 \%$ no Estado, enquanto o do rebanho ovino diminuiu 55\%. O rebanho bovino total do Estado ficou estacionário no período e seu impacto positivo sobre o VAB agrícola pode ter ocorrido pelo aumento na taxa de desfrute.

1. Constant

2. Varia

2.1. arro

2.2. feijã

2.3. fum

2.4. mill

2.5. soja

2.6. trig

2.7. maç

2.8. uva

3. Variação

3.1. bov

3.2. ovir

3.3. suín

3.4. ave

3.5. Leit

4. Efeito di

4.1. Sul

4.2. Nor

5. Percentu

6. Percentu 
A taxa de crescimento da agropecuária tendeu a ser maior nas regiões de pequenos e médios estabelecimentos rurais.

\section{Conclusões}

As perspectivas de crescimento econômico dos municípios do Rio Grande do Sul são otimistas. No período inicial, $22 \%$ das regiões apresentaram um VAB per capita inferior a 56\% do valor médio estadual. A projeção indica que, no futuro, apenas $3 \%$ das regiões se manterão neste nível. Dos $72 \%$ das regiões do Estado que apresentaram, no inicio, um VAB per capita inferior ao valor médio estadual, ficarão apenas $48 \%$ delas, no futuro.

Apenas as regiões que, inicialmente, já apresentaram um VAB per capita mais elevado terão crescimento econômico influenciado, positivamente, se situadas em microrregiões homogêneas com VAB per capita mais alto.

Os efeitos dos setores indústria e serviços sobre o crescimento do VAB per capita foram mais importantes do que o do setor agropecuário. A importância deste setor para a evolução do VAB per capita se destaca, porém, na mesorregião noroeste do Estado.

O crescimento do VAB industrial foi influenciado pela indústria mecânica; borracha, fumo e couro; química; calçados; e alimentos e bebidas. $\mathrm{O}$ crescimento do VAB do setor serviços foi influenciado, positivamente, pelos serviços de utilidade pública; pela construção civil; pelo comércio varejista; pela administração técnica e profissional; pela administração pública; e, negativamente, pelas instituições financeiras.

Houve impacto positivo na evolução do VAB do setor agropecuário das produções de soja, trigo, fumo, uva e variações nos efetivos de bovinos, suínos e aves. A variação no efetivo ovino teve impacto negativo no crescimento do VAB agropecuário. 
O crescimento do VAB serviços foi menor nas regiões Sul e Noroeste, em comparação ao da região Nordeste. Não houve diferenças regionais nas taxas de crescimento do VAB da indústria e da agropecuária.

Nas regiões onde predominam os estabelecimentos rurais menores, as taxas de crescimento do VAB industrial, de serviços e do setor agropecuário foram maiores. É que a maioria das atividades industriais e de serviços que apresentaram impacto positivo nas taxas de crescimento dos respectivos setores está localizada em regiões com essa estrutura agrária.

Quanto ao setor agropecuário, pode-se afirmar que muitas das atividades relacionadas com maiores taxas de crescimento do VAB agropecuário, como fumo, uva, aves, suínos, são exercidas nos estabelecimentos rurais menores.

Para concluir, pode-se afirmar que os três setores, indústria, serviços e agropecuária, estão contribuindo para as perspectivas otimistas de crescimento econômico regional no Estado, mas o setor agropecuário, apesar do menor coeficiente de correlação parcial entre a taxa de crescimento do VAB e a do VAB per capita, se destaca porque a sua atuação também ocorre por meio do setor industrial, no qual várias das atividades com impactos positivos são ligadas ao agronegócio como borracha, fumo, couro, calçados, alimentos e bebidas. Além disto, atua via setor de serviços, no qual o comércio varejista de alimentos e demais derivados do setor agropecuário são importantes.

\section{Referências bibliográficas}

ACCURSO, J. S. A economia gaúcha nos anos 90. In: Fligenspan, F. B., org. Economia gaúcha e reestruturação nos anos 90. Porto Alegre. FEE. 2000

BARRO, R.J. e SALA-I-MARTIN, X.. Convergence across States and Regions. Brookings Papers on Economic Activity, 1991, p.107-182. 
BARRO, R.J. e SALA-I-MARTIN, X. Convergence. Journal of Political Economy. 100, 1992, p.223-251.

BASTOS, R. L. A. Produto e emprego nas regiões do Rio Grande do Sul, nos anos 90: uma abordagem exploratória dos Conselhos Regionais de Desenvolvimento. Indicadores Econômicos FEE. Porto Alegre. v. 29. n. 4, 2002, p. 245-271.

BAUMOL, W.J. Productivity growth, convergence, and welfare: what the long-run data how, American Economic Review, 54, 1986, p.10721085.

JARDIM, M. de L. T. Dinâmica demográfica do Rio Grande do Sul. In: Fligenspan, F. B., org. Economia gaúcha e reestruturação nos anos 90. Porto Alegre. FEE. 2002.

LE GALLO, J. Space-time analysis of GDP disparities among European regions: A Markov chains approach. Dijon/França: University of Burgundy, Março 2001.

MAGRINI, S. The evolution of income disparities among the regions of the European Union. Regional Science and Urban Economics, No 29, 1999.

REY, S. J. Spatial Dependence in the Evolution of Regional Income Distributions. San Diego State University. Estados Unidos. Maio 2001.

SIEGEL, S. Nonparametric Statistics for the Behavioral Sciences. Nova Iorque: McGraw-Hill Book Company, 1956.

SIMON, C. P. e BLUME, L. Matemática para Economistas. Artmed Editora S.A. Porto Alegre. 2004.

SOUZA, N. de J. de. Desenvolvimento Econômico. Editora Atlas S. A. São Paulo. 1995. 
STULP, V. J. e FOCHEZATTO, A. A evolução das disparidades regionais no Rio Grande do Sul: uma aplicação de matrizes de Markov. Nova Economia. v.14 No 1 Belo Horizonte MG. 2004, p.39-66.

Abstract. The study analyses the convergence or not of the counties of the state of Rio Grande do Sul to a same level of income per capita. It also examines variables associated with the economic growth of the counties, such as the regional location, the participation of the economic sectors and the agrarian structure. The perspectives of regional economic growth in the State are promising. In the long run the percentage of counties with income per capita above the State average would increase from $28 \%$ to $52 \%$. The effect of the industrial and services sectors upon the growth of income is greater than that of the agricultural sector, with the exception in the State's Norwest region. But the agricultural sector is important for the counties economic growth because, besides its direct effect, its contribution also occurs through the industrial and services sectors related to agriculture such as rubber, tobacco, leather, shoes, food, beverages and retail sales. Income grows at higher rates in the regions where the smaller farms are predominant.

Key-words: economic growth, counties, regional convergence. 
Valter José Stülp ${ }^{2}$

\section{Anexos}

Quadro 1 - Valores do VAB per capita das regiões ou municípios geograficamente idênticos de 1990 a 2000. Valores relativos ao VAB per capita do RS, em cada ano, considerado igual à unidade

\begin{tabular}{|c|c|c|c|c|c|c|c|c|}
\hline \multirow{2}{*}{$\begin{array}{l}\text { Regiões ou } \\
\text { municípios }\end{array}$} & \multicolumn{2}{|c|}{ Ano } & \multirow{2}{*}{ Regiões ou municípios } & \multicolumn{2}{|c|}{ Ano } & \multirow[t]{2}{*}{ Regiões ou municípios } & \multicolumn{2}{|c|}{ Ano } \\
\hline & 1990 & 2000 & & 1990 & 2000 & & 1990 & 2000 \\
\hline 1 & 0,76 & 0,86 & 2 & 0,66 & 1,08 & 3 & 1,69 & 1,79 \\
\hline 4 & 0,66 & 0,84 & 5 & 0,57 & 0,66 & 6 & 0,61 & 0,71 \\
\hline 7 & 0,80 & 0,66 & 8 & 1,62 & 1,57 & 9 & 0,59 & 0,99 \\
\hline 10 & 0,63 & 0,92 & 11 & 1,24 & 1,12 & 12 & 1,24 & 1,21 \\
\hline 13 & 0,47 & 0,62 & 14 & 0,69 & 0,57 & 15 & 0,83 & 0,83 \\
\hline 16 & 0,81 & 0,88 & 17 & 0,73 & 0,84 & 18 & 2,13 & 2,32 \\
\hline 19 & 0,44 & 0,58 & 20 & 0,89 & 0,98 & 21 & 0,61 & 1,14 \\
\hline 22 & 0,82 & 0,90 & 23 & 0,77 & 0,86 & 24 & 0,45 & 0,51 \\
\hline 25 & 0,63 & 0,70 & 26 & 0,72 & 0,68 & 27 & 1,61 & 2,01 \\
\hline 28 & 0,65 & 1,10 & 29 & 1,22 & 1,28 & 30 & 0,85 & 0,95 \\
\hline 31 & 0,55 & 0,75 & 32 & 0,77 & 0,71 & 33 & 1,19 & 0,89 \\
\hline 34 & 1,39 & 1,71 & 35 & 0,47 & 0,59 & 36 & 0,73 & 0,86 \\
\hline 37 & 0,82 & 0,81 & 38 & 1,45 & 1,16 & 39 & 1,57 & 1,91 \\
\hline 40 & 1,05 & 0,85 & 41 & 1,32 & 1,16 & 42 & 1,28 & 0,99 \\
\hline 43 & 0,58 & 0,61 & 44 & 3,49 & 0,60 & 45 & 1,15 & 1,01 \\
\hline 46 & 0,56 & 0,76 & 47 & 0,52 & 0,78 & 48 & 0,56 & 0,56 \\
\hline 49 & 0,81 & 0,57 & 50 & 0,49 & 0,64 & 51 & 0,61 & 0,81 \\
\hline 52 & 0,66 & 0,69 & 53 & 1,19 & 0,67 & 54 & 1,73 & 1,57 \\
\hline 55 & 0,50 & 0,52 & 56 & 1,22 & 0,82 & 57 & 0,61 & 0,65 \\
\hline 58 & 0,58 & 0,50 & 59 & 0,64 & 0,63 & 60 & 0,76 & 0,81 \\
\hline 61 & 0,84 & 0,69 & 62 & 0,71 & 0,65 & 63 & 0,73 & 0,68 \\
\hline 64 & 0,75 & 0,78 & 65 & 0,54 & 0,76 & 66 & 0,64 & 0,59 \\
\hline 67 & 0,68 & 0,66 & 68 & 0,51 & 0,67 & 69 & 1,55 & 1,53 \\
\hline 70 & 051 & 0,52 & 71 & 0,56 & 0,52 & 72 & 0,74 & 0,87 \\
\hline 73 & 1,30 & 1,13 & 74 & 0,48 & 0,59 & 75 & 0,46 & 0,44 \\
\hline 76 & 1,91 & 2,57 & 77 & 0,45 & 0,53 & 78 & 0,71 & 0,76 \\
\hline 79 & 0,69 & 0,78 & 80 & 0,76 & 0,59 & 81 & 0,60 & 0,82 \\
\hline 82 & 1,02 & 1,33 & 83 & 0,51 & 0,75 & 84 & 0,89 & 0,93 \\
\hline Agudo & 0,72 & 0,81 & Alegria & 0,57 & 0,65 & Alpestre & 0,47 & 0,66 \\
\hline Alto Alegre & 0,84 & 0,83 & Alvorada & 0,27 & 0,28 & Amaral Ferrador & 0,45 & 0,54 \\
\hline André da Rocha & 1,39 & 2,34 & Antonio Prado & 1,07 & 1,32 & Arroio do Sal & 0,59 & 0,64 \\
\hline Arroio dos Ratos & 0,70 & 0,52 & Arroio Grande & 0,71 & 0,82 & Barracão & 0,48 & 0,76 \\
\hline Barros Cassal & 0,38 & 0,52 & Bom Princípio & 0,92 & 1,05 & Boqueirão do Leão & 0,56 & 0,67 \\
\hline Bossoroca & 1,22 & 0,87 & Braga & 0,61 & 0,66 & Caçapava do Sul & 0,60 & 0,66 \\
\hline Cacequi & 0,71 & 0,68 & Cachoeirinha & 0,91 & 1,03 & Caiçara & 0,53 & 0,86 \\
\hline Camargo & 1,04 & 1,90 & Cambará do Sul & 0,88 & 0,84 & Campo Bom & 2,18 & 2,25 \\
\hline Campos Borges & 0,96 & 0,69 & Cândido Godói & 0,98 & 0,84 & Canela & 0,72 & 0,52 \\
\hline Canguçu & 0,47 & 0,49 & Capão do Leão & 1,22 & 0,80 & Capela de Santana & 0,51 & 0,61 \\
\hline Carlos Barbosa & 1,85 & 1,70 & Caxias do Sul & 1,57 & 1,62 & Cerro Branco & 0,68 & 0,81 \\
\hline Charqueadas & 1,28 & 1,11 & Colorado & 1,33 & 1,13 & Condor & 1,15 & 1,09 \\
\hline Coronel Bicaco & 0,63 & 0,85 & Cotiporã & 0,80 & 0,87 & Crissiumal & 0,60 & 0,78 \\
\hline Cristal & 0,65 & 0,66 & $\begin{array}{l}\text { Dezesseis de } \\
\text { Novembro }\end{array}$ & 0,58 & 0,59 & Dom Feliciano & 0,41 & 0,58 \\
\hline Dom Pedrito & 0,82 & 0,88 & Dona Francisca & 0,69 & 0,80 & $\begin{array}{l}\text { Doutor } \\
\text { Cardoso }\end{array}$ & 0,60 & 0,70 \\
\hline Eldorado do Sul & 3,33 & 2,18 & Encruzilhada do Sul & 0,50 & 0,57 & Entre Rios do Sul & 1,09 & 1,17 \\
\hline Entre-Ijuis & 0,83 & 0,79 & Erebango & 1,07 & 0,97 & Erval Grande & 0,51 & $0,5 \varepsilon$ \\
\hline Estação & 1,34 & 1,09 & Estância Velha & 1,91 & 1,65 & Esteio & 1,65 & 1,32 \\
\hline Eugênio de Castro & 0,98 & 1,00 & Fagundes Varela & 0,81 & 2,23 & Farroupilha & 2,59 & 1,51 \\
\hline
\end{tabular}


Quadro 1, continuação

Fonte: Baseado em dados da Fundação de Economia e Estatística do RS (FEE).

*Nota: As regiões, indicadas por números neste quadro, são definidas no quadro 2.

Faxinalzinho Frederico West Gramado Harmonia Ibirubá Imbé Ipiranga do Sul Ivorá Jaquirana Lavras do Sul Marcelino Ram Maximiliano de Morro Redondo Nova Araçá

Nova Prata Paim Filho

Parai

Paverama

Pirapó

Portão

Pouso Novo

Quarai

Restinga Seca

Rolante

Rosário do Sul

Santa Bárbara

Santana do Liv

São Francisco

São José do He

São Leopoldo São Nicolau

São Vendelino 


\section{Quadro 2 - Municípios integrantes em 2000 das regiões geograficamente idênticas de 1990 a 2000 e constituídas por mais de um município}

\begin{tabular}{|c|c|c|c|}
\hline Região & Municípios & Região & Municípios \\
\hline 1 & Ajuricaba e Nova Ramada & 2 & Aratiba e Barra do Rio Azul \\
\hline 3 & $\begin{array}{l}\text { Arroio do Meio, Capitão, Coqueiro Baixo, Nova } \\
\text { Bréscia, Relvado e Travesseiro. }\end{array}$ & $\begin{array}{l}4 \\
5\end{array}$ & $\begin{array}{l}\text { Arroio do Tigre e Estrela Velha } \\
\text { Arvorezinha e Itapuca }\end{array}$ \\
\hline 7 & $\begin{array}{l}\text { Aceguá, Bagé, Candiota, Herval, Hulha Negra, Pedras } \\
\text { Altas e Pinheiro Machado. }\end{array}$ & $\begin{array}{l}6 \\
8\end{array}$ & $\begin{array}{l}\text { Áurea e Centenário } \\
\text { Barão, Bento Gonçalves, Boa Vista do Sul, } \\
\text { Colinas, Coronel Pilar, Estrela, Garibaldi, }\end{array}$ \\
\hline 9 & Boa Vista do Buricá e Nova Candelária. & & Monte Belo do Sul, Pinto Bandeira, Roca Sales \\
\hline 10 & Bom Jesus e São José dos Ausentes. & & e Santa Tereza. \\
\hline 11 & Bom Retiro e Fazenda Vilanova & 12 & Brochier, Maratá, Montenegro, Pareci Novo, \\
\hline 13 & Butiá e Minas do Leão. & & Salvador do Sul, São José do Sul e São Pedro \\
\hline 14 & Cachoeira do Sul e Novo Cabrais. & & da Serra. \\
\hline 15 & Caibaté e Mato Queimado. & 16 & Campinas do Sul e Cruzaltense. \\
\hline \multirow[t]{2}{*}{17} & $\begin{array}{l}\text { Bom Progresso, Campo Novo, Esperança } \\
\text { do Sul. Humaitá Tiradentes do Sul e }\end{array}$ & $\begin{array}{l}18 \\
19\end{array}$ & $\begin{array}{l}\text { Canoas e Nova Santa Rita. } \\
\text { Capão da Canoa e Xangri-lá }\end{array}$ \\
\hline & Três Passos. & 20 & Almirante Tamandaré, Barra Funda, \\
\hline 21 & Casca e Santo Antonio do Palma. & & Carazinho, Chapada, Ciriaco, Coqueiros \\
\hline 22 & $\begin{array}{l}\text { Cerro Largo, Salvador das Missões e São } \\
\text { Pedro do Butiá. }\end{array}$ & & $\begin{array}{l}\text { do Sul, Coxilha, David Canabarro, } \\
\text { Gentil, Ibiraiaras, Lagoa dos Três }\end{array}$ \\
\hline $\begin{array}{l}23 \\
24 \\
25 \\
26\end{array}$ & $\begin{array}{l}\text { Catuípe, Chiapeta e Inhacorá. } \\
\text { Balneário Pinhal e Cidreira. } \\
\text { Constantina, Engenho Velho, Novo Xingu. } \\
\text { Augusto Pestana, Boa Vista do Cadeado, } \\
\text { Boa Vista do Incra, Bozano, Coronel } \\
\text { Barros, Cruz Alta, Fortaleza dos Valos e }\end{array}$ & & $\begin{array}{l}\text { Cantos, Marau, Mato Castelhano, } \\
\text { Muliterno, Não-Me-Toque, Nicolau } \\
\text { Vargueiro, Nova Boa Vista, Passo } \\
\text { Fundo, Pontão, Ronda Alta, Santo } \\
\text { Antonio do Planalto, Sarandi, Sertão e } \\
\text { Tapera. }\end{array}$ \\
\hline & Ijuí. & 27 & Dois Irmãos e Morro Reuter. \\
\hline 28 & Dois Lajeados e São Valentim do Sul & 29 & Anta Gorda, Doutor Ricardo e Encantado. \\
\hline 30 & Barão do Cotegipe, Erechim, Jacutinga & 31 & Dois Irmãos das Missões e Erval Seco. \\
\hline & Paulo Bento, Ponte Preta e Quatro & 32 & Faxinal do Soturno e São João do Polêsine. \\
\hline & Irmãos. & 33 & Alto Feliz, Feliz, Linha Nova e Vale Real. \\
\hline 34 & Flores da Cunha e Nova Pádua. & 35 & General Câmara e Vale Verde. \\
\hline 36 & Campinas das Missões, Giruá, Guarani & 37 & Guaporé e União da Serra. \\
\hline & das Missões, Senador Salgado Filho, & 38 & Itaqui e Maçambará. \\
\hline & Sete de Setembro e Ubiretama. & 39 & Ivoti, Lindolfo Collor, Nova Petrópolis, \\
\hline 40 & $\begin{array}{l}\text { Júlio de Castilhos, Nova Palma, Pinhal } \\
\text { Grande e Quevedo. }\end{array}$ & & $\begin{array}{l}\text { Picada Café, Presidente Lucena e Santa } \\
\text { Maria do Herval }\end{array}$ \\
\hline 41 & $\begin{array}{l}\text { Canudos do Vale, Forquetinha, Lajeado, } \\
\text { Marques de Souza, Progresso, Santa } \\
\text { Clara do Sul e Sério. }\end{array}$ & $\begin{array}{l}42 \\
43\end{array}$ & $\begin{array}{l}\text { Muçum e Vespasiano Correa. } \\
\text { Gramado dos Loureiros, Nonoai e Rio dos } \\
\text { Indios }\end{array}$ \\
\hline $\begin{array}{l}44 \\
46\end{array}$ & $\begin{array}{l}\text { Maquine e Osório } \\
\text { Boa Vista das Missões, Cerro Grande, Jaboticaba, } \\
\text { Lajeado do Bugre, Novo Barreiro, Palmeira das } \\
\text { Missões, Sagrada Família, São José das Missões, São } \\
\text { Pedro das Missões }\end{array}$ & $\begin{array}{l}45 \\
47 \\
48 \\
49\end{array}$ & $\begin{array}{l}\text { Capivari do Sul e Palmares do Sul } \\
\text { Palmitinho e Pinheiro do Vale } \\
\text { Cerrito e Pedro Osório. } \\
\text { Arroio do Padre, Pelotas, São Lourenço do Sul } \\
\text { e Turuçu. }\end{array}$ \\
\hline 51 & Alecrim, Porto Lucena, Porto Verra Cruz e Santo Cristo. & 50 & $\begin{array}{l}\text { Ametista do Sul, Cristal do Sul, Irai, Novo } \\
\text { Tiradentes, Planalto, Rodeio Bonito e Seberi }\end{array}$ \\
\hline 52 & Passo do Sobrado e Rio Pardo. & 53 & Espumoso, Jacuizinho, Salto do Jacuí. \\
\hline 54 & $\begin{array}{l}\text { Candelária, Gramado Xavier, Herveiras, Santa Cruz do } \\
\text { Sul, Sinimbu e Vale do Sol }\end{array}$ & 55 & $\begin{array}{l}\text { Dilermando de Aguiar, Itaiara, Santa Maria e } \\
\text { São Martinho da Sera. }\end{array}$ \\
\hline 57 & $\begin{array}{l}\text { Capão do Cipó, Jarí, Santiago, São Miguel das Missões, } \\
\text { Tupanciretã e Unistalda. }\end{array}$ & $\begin{array}{l}56 \\
58 \\
59 \\
60\end{array}$ & $\begin{array}{l}\text { Chuí e Santa Vitória do Palmar. } \\
\text { Santo Ângelo e Vitória das Missões. } \\
\text { Caraá e Santo Antônio da Patrulha. } \\
\text { Santo Augusto e São Valério do Sul. }\end{array}$ \\
\hline
\end{tabular}


REVISTA DE ECONOMIA E AGRONEGÓCIO, VOL.3, $N^{\circ} 4$

\begin{tabular}{|c|c|c|c|}
\hline Região & Municípios & Região & Municípios \\
\hline $\begin{array}{l}61 \\
63\end{array}$ & $\begin{array}{l}\text { Garruchos e São Borja. } \\
\text { Santa Margarida do Sul, São Gabriel, São }\end{array}$ & 62 & $\begin{array}{l}\text { Alegrete, Manoel Viana e São Francisco de } \\
\text { Assis. }\end{array}$ \\
\hline 65 & $\begin{array}{l}\text { Sepé e Vila Nova do Sul. } \\
\text { Cacique Doble, Santo Expedito do Sul, São } \\
\text { José do Ouro e Tupanci do Sul. }\end{array}$ & 64 & $\begin{array}{l}\text { Arambaré, Barão do Triunfo, Barra do Ribeiro, } \\
\text { Camaquã, Cerro Grande do Sul, Chuvisca, } \\
\text { Guaíba, Mariana Pimentel, São Jerônimo, }\end{array}$ \\
\hline $\begin{array}{l}66 \\
67\end{array}$ & $\begin{array}{l}\text { Rolador e São Luiz Gonzaga. } \\
\text { São Pedro do Sul e Toropi. }\end{array}$ & & Sertão Santana e Tapes. \\
\hline 68 & Benjamin Constant do Sul e São Valentim. & $\begin{array}{l}69 \\
70\end{array}$ & $\begin{array}{l}\text { Araricá, Nova Hartz e Sapiranga. } \\
\text { Lagoa Bonita do Sul, Passa Sete e Sobradinho. }\end{array}$ \\
\hline $\begin{array}{l}71 \\
72\end{array}$ & $\begin{array}{l}\text { Mormaço e Soledade. } \\
\text { Água Santa, Caseiros, Charrua, Floriano } \\
\text { Peixoto, Ibiaçá, Santa Cecília do Sul, } \\
\text { Tapejara e Vila Lângaro. }\end{array}$ & $\begin{array}{l}73 \\
74\end{array}$ & $\begin{array}{l}\text { Tabaí e Taquari. } \\
\text { Barra do Guarita, Derrubadas e Tenente Portela. }\end{array}$ \\
\hline $\begin{array}{l}75 \\
77\end{array}$ & $\begin{array}{l}\text { Itati e Terra de Areia. } \\
\text { Dom Pedro de Alcântara, Mampituba, } \\
\text { Morrinhos do Sul, Torres e Três Forquilhas. }\end{array}$ & $\begin{array}{l}76 \\
78 \\
79\end{array}$ & $\begin{array}{l}\text { Imigrante, Teutônia e Westfalia. } \\
\text { São José do Inhacorá e Três de Maio. } \\
\text { Novo Machado, Porto Mauá, Tucunduva e } \\
\text { Tuparendi. }\end{array}$ \\
\hline $\begin{array}{l}80 \\
82\end{array}$ & $\begin{array}{l}\text { Barra do Quaraí e Uruguaiana. } \\
\text { Cruzeiro do Sul, Mato Leitão e Venâncio } \\
\text { Aires. }\end{array}$ & 81 & $\begin{array}{l}\text { Campestre da Serra, Capão Bonito do Sul, } \\
\text { Esmeralda, Lagoa Vermelha, Monte Alegre dos } \\
\text { Campos, Muitos Capões, Pinhal da Serra e }\end{array}$ \\
\hline $\begin{array}{l}83 \\
84\end{array}$ & $\begin{array}{l}\text { Carlos Gomes e Viadutos } \\
\text { Ernestina, Ibirapuitã, Tio Hugo e Victor } \\
\text { Graeff. }\end{array}$ & & \\
\hline
\end{tabular}

Fonte: Baseado no histórico das emancipações municipais disponível na Fundação de Economia e Estatística do RS. 